\title{
Virus Mimetic Poly (I:C)-primed Airway Exosomes Enter Brain and Induce Mitochondrial Reactive Oxygen Species in Microglia
}

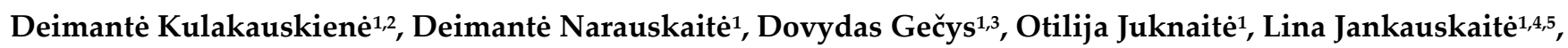 \\ Aistè Masaityte் ${ }^{6}$, Jurgita Šventoraitiené ${ }^{6}$, Hermanas Inokaitis ${ }^{6}$, Zoja Mikniené ${ }^{7}$, Ilona Sadauskiené ${ }^{8}$, Zbigniev \\ Balion ${ }^{1,9}$, Ramunè Morkūnienè2, Neringa Paužiené ${ }^{6}$, Dainius H. Pauža ${ }^{6}$, Aistė Jekabsone ${ }^{1,10}$ *
}

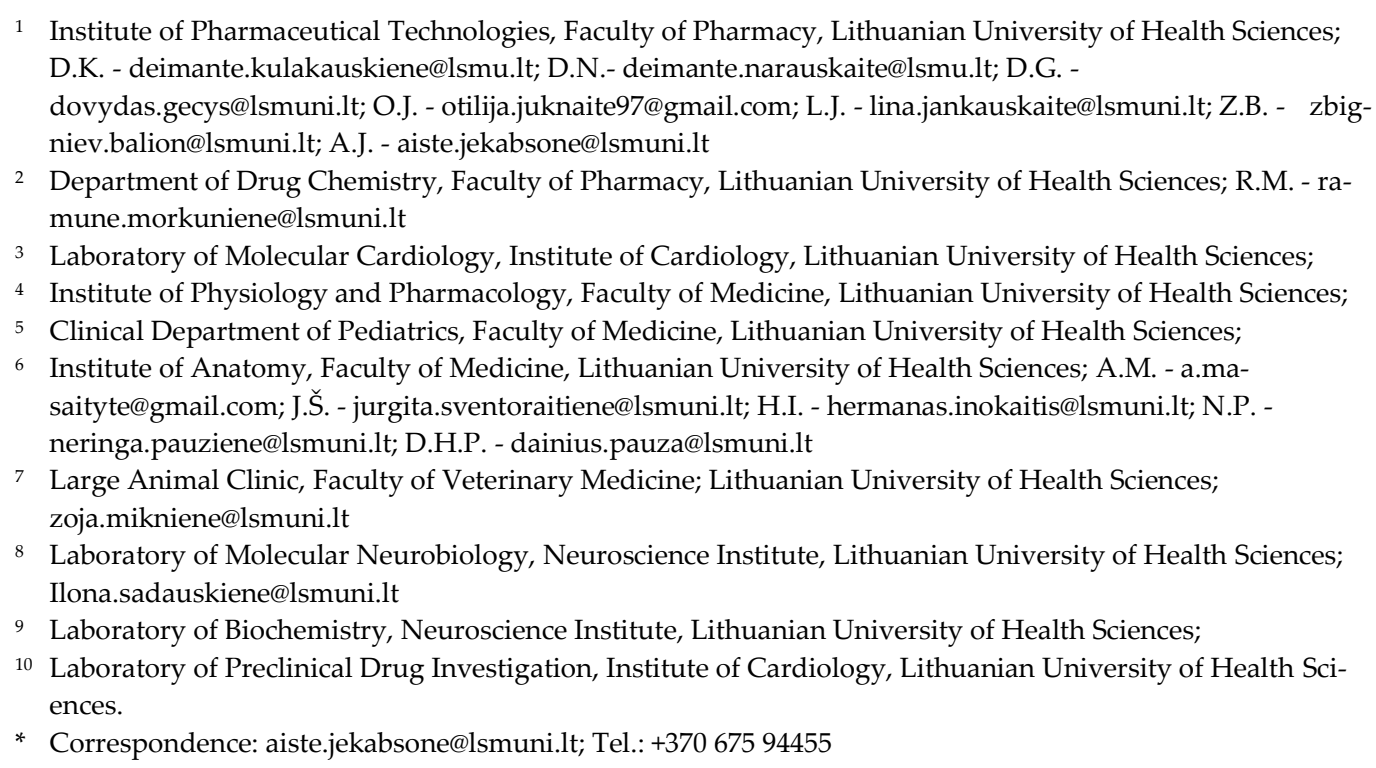

Simple Summary: Upper respiratory tract viral infections are among the most common diseases. The blood-brain barrier protects the brain from direct invasion of pathogens. However, the cells share their content with other cells in small nanovesicles called exosomes that can travel long distances and cross biological barriers. Virus-infected cell exosomes might transmit inflammatory signals or even viral particles to other cells. If they would carry such signals or particles to the central nervous system, it might cause neuroinflammation. However, the migration and impact of virusprimed airway exosomes on the brain have not been studied yet. Therefore, the study aimed to track airway exosomes from the respiratory tract to the brain and determine how infection-primed exosomes affect microglia - the cells responsible for immune response in the brain. The study revealed that airway cell exosomes enter the brain within an hour and gather in microglia. Interestingly, many airway exosomes were found in the hippocampus, the region most affected by Alzheimer's disease. Moreover, exosomes from virus-infected airway cells stimulated reactive oxygen species in microglia. The elevated level of reactive oxygen species is one of the features of microglial inflammatory activation. Thus, airway cells indeed might communicate inflammatory information to the brain during viral infection.

Abstract: Viral infections induce exosomes containing viral material and inflammatory factors. Dur-
ing respiratory tract infection, exosomes can easily cross the blood-brain barrier and transmit the
inflammatory signal to the brain; however, such a hypothesis has no experimental evidence. The
study investigated whether exosomes from virus mimetic poly (I:C)-primed airway cells enter the
brain and interact with brain immune cells microglia. Airway cells were isolated from Wistar rats
and BALB/c mice; microglial cell cultures - from Wistar rats. Exosomes from poly (I:C)-stimulated
airway cell culture medium were isolated by precipitation, visualised by transmission electron mi-
croscopy, and evaluated by nanoparticle analyser; exosomal markers CD81 and CD9 were 
determined by ELISA. For in vitro and in vivo tracking, exosomes were loaded with Alexa Fluor 555labelled RNA. Intracellular reactive oxygen species (ROS) were evaluated by DCFDA fluorescence and mitochondrial superoxide - by MitoSOX. The exosomes from poly (I:C)-primed airway cells entered the brain within an hour after intranasal introduction, were internalised by microglia, and induced intracellular and intramitochondrial ROS production. There was no ROS increase in microglial cells was after treatment with exosomes from airway cells untreated with poly (I:C). The data indicate that virus-primed airway cell exosomes might enter the brain and induce the activation of microglial cells.

Keywords: airway cell exosomes; viral infection; microglia; mitochondria; reactive oxygen species.

\section{Introduction}

The upper respiratory tract is considered a gateway for viruses to enter the human body. Approximately $90 \%$ of the upper airway tract infections are caused by viruses [1], and over 200 different viruses have been isolated from the human upper respiratory tract [2]. Generally, respiratory viruses, such as rhinoviruses, influenza, adenoviruses, enteroviruses, does not spread to the distant tissues; however, accumulating evidence shows that viral material carried by extracellular vesicles (EVs) originating from infected cells might induce cellular alterations outside of the respiratory tract [3-5].

Exosomes are 30-150 nm diameter extracellular vesicles essential for intercellular communication [6]. They are secreted by almost every cell type and present in various body fluids, including urine, blood, breast milk, and saliva [7]. Exosomes contain different bioactive molecules such as proteins, lipids and several RNA species [8]. Studies have shown that exosomal cargo depends on the physiological state of the parental cell $[3,9,10]$. It was observed that exosome content alternates in response to viral infection and that exosomes isolated from infected cells were able to activate innate immune response [3]. Several studies have shown that viral material transported by EVs can induce immune response [11], viral replication [12], cell apoptosis, cytokine release suppression [13,14], as well as contribute to NLRP3 inflammasome and IL-1 $\beta$ production [15]. Additionally, it was well established that exosomes can effectively cross the blood-brain barrier and carry endogenous material to the brain from the peripheral circulatory system $[16,17]$.

One of the most plausible exosome recipients in the brain are microglial cells. Microglia and non-parenchymal macrophages in the brain are mononuclear phagocytes that are essential in brain homeostasis. Microglia constitute $5-10 \%$ of total brain cells and are the only true CNS parenchymal macrophages that can interact with neurons, astrocytes and oligodendrocytes $[18,19]$. Microglia are involved in synaptic plasticity by synaptic pruning in the developing and adult brain; they also phagocytose dying, dead, and sometimes healthy cells [20-22]. Additionally, microglia respond to an infection or brain damage by transforming into an active inflammatory phenotype and protecting the brain from pathogens. However, prolonged microglial activation might lead to neurodegenerative disease development [23]. Recent evidence indicates that peripheral infections can stimulate an immune response in the brain, causing irreversible genetic and epigenetic changes in brain immune cells leading to the formation of immune memory [24]. Antiviral immune response and immune memory formation are related to rearrangements in mitochondrial network and dynamics and involve reactive oxygen species (ROS) signalling [25]. Exosomes might carry viral particles and/or inflammatory molecules. One might speculate that exosomes produced during frequent recurrent viral respiratory infections might cause microglia activation and maintenance of immune reactivity in the brain. However, such a hypothesis has no experimental evidence yet. This study investigates whether exosomes from virus mimetic TLR-3 agonist poly (I:C)-affected airway cell exosomes can enter the brain and how they interact with brain immune cells microglia. 


\section{Materials and Methods}

\subsection{Experimental design}

The experimental design of the study is represented in Figure 1. First of all, airway cells were isolated from laboratory rodent lungs, cultivated and primed with poly (I:C). Then, exosomes were isolated, characterised and prepared for in vivo intranasal and in vitro cell culture introduction. In parallel, primary microglial culture was prepared. Next, the poly (I:C)-treated and untreated airway exosomes were introduced to cultivated microglia, and the cultures were monitored for exosome internalisation and intracellular plus intramitochondrial ROS production. In addition, stained airway cell exosomes were intranasally introduced to laboratory mice, and exosome localisation in immunostained microglial cells in the brain cryosections was monitored after 1, 2, 3, and 5 hours.

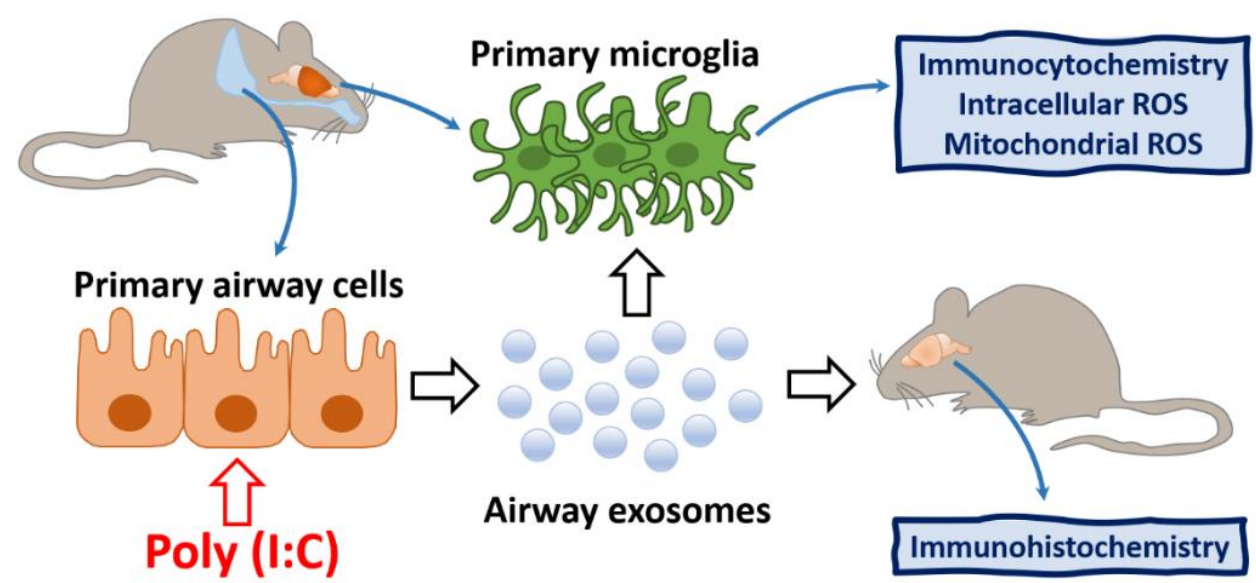

Figure 1. The experimental design of the study. Primary airway cells of rodent origin were treated with poly (I:C), and their exosomes were applied on microglial cell cultures and intranasally to mice. Microglial cells in vitro and in vivo were investigated for exosome internalisation, and cultured microglia were analysed for intracellular and intramitochondrial ROS production.

\subsection{Culture of primary airway cells}

Primary airway cells were prepared from 6-7-day-old Wistar rats for in vitro studies, and primary mouse airway cells for in vivo studies were made from 9-11 weeks old Balb/c mice for in vivo experiments. All experimental procedures were performed according to the Republic of Lithuania Law on the Care, Keeping and Use of Animals. The mice were maintained and handled at the Lithuanian University of Health Sciences animal house in agreement with the ARRIVE guidelines.

For isolation of airway cells, the animals were sacrificed by cervical dislocation. The trachea and lungs were exposed and removed from the thorax. After, the heart, trachea and large bronchi were removed. The remaining lung tissue was rinsed twice with PBS, further processed in DMEM and manually homogenised with the sharp scissors. Pieces of lung tissue were transferred into a conical tube, and $5 \mathrm{ml}$ of digestion medium (DMEM, $1 \%$ trypsin) was added. Then, the tube with the tissue was incubated for up to $30 \mathrm{~min}$ at $37^{\circ} \mathrm{C}$ by gentle rocking every $15 \mathrm{~min}$. After incubation, the digestion process was inactivated with the DMEM and 10\% FBS. Further, all tissue pieces were filtered through the $70-\mu \mathrm{m}$ cell strainer to obtain a single-cell suspension. The strainer was discarded, and the tube was further centrifuged at $1200 \mathrm{rpm}$ for $10 \mathrm{~min}$ at $4^{\circ} \mathrm{C}$. The supernatant was removed, cells were suspended in the, counted, seeded, and cultivated in a T-75 flask with a growth medium (DMEM with GlutaMAX ${ }^{\mathrm{TM}}$, 10\% FBS and 1\%, or $10000 \mathrm{IU} / \mathrm{mL}$, penicillin- 
streptomycin solution). After $24 \mathrm{~h}$, the supernatant was removed and centrifuged again. All adherent cells (fibroblasts) were discarded. The centrifuged cells were then seeded and cultivated in a T-75 flask in the growth medium until further experiments.

\subsection{Cultures of primary mixed glia and pure microglia}

Mixed glial and pure microglial cultures were prepared from 6-7-day-old Wistar rat pups, as described in [26], with minor modifications. All animal care and procedures were performed according to the Republic of Lithuania Law on the Care, Keeping and Use of Animals following ARRIVE guidelines. Briefly, after decapitation, cerebral cortices were separated from the remaining parts of the brain and placed in Petri dishes containing PBS, glucose $(13 \mathrm{mM})$, and penicillin-streptomycin solution $(10000 \mathrm{IU} / \mathrm{mL}-10000 \mu \mathrm{g} / \mathrm{mL})$. After removing the meninges, the cortical tissues were cut and transferred to the centrifugal tube with preheated $\left(37^{\circ} \mathrm{C}\right)$ Versene $\left(\mathrm{Gibco}^{\mathrm{TM}}\right.$, USA, 1:50000) solution and incubated for $10 \mathrm{~min}$ in $37^{\circ} \mathrm{C}$ with gentle agitation. After incubation, the solution was tittered and centrifuged at $290 \times g$ at room temperature. The pellet was resuspended in cell growth media (DMEM with GlutaMAX ${ }^{\mathrm{TM}}$ and 10\% FBS). The resuspended cells were passed through $40 \mu \mathrm{m}$ mesh, transferred to poly-L-lysine coated T-75 flasks and cultivated for 13 days replacing growth medium every $5^{\text {th }}$ day. Microglial cells were isolated by gently shaking the flask for $5 \mathrm{~min}$ on an orbital shaker. Media with detached microglial cells were collected and pelleted by centrifugation at $290 \mathrm{~g}$ for $5 \mathrm{~min}$. Microglial cells were further cultivated in T-75 flasks using DMEM-GlutaMAX ${ }^{\mathrm{TM}}$ growth medium supplemented with $10 \%$ FBS and $1 \%$ penicillin-streptomycin solution.

\subsection{Exosome isolation}

Rat and mouse airway cells were cultured in $75 \mathrm{~cm}^{2}$ flasks, in $75 \mathrm{~cm} 2$ flasks, in DMEMGlutaMAX ${ }^{\mathrm{TM}}$ medium with 10\% FBS, $25 \mathrm{mM}$ HEPES, and 1\% penicillin-streptomycin solution at $37^{\circ} \mathrm{C}$. After reaching $70-80 \%$ confluency, the growth medium was replaced to FBSdepleted composition to avoid contamination with EVs that are present in the serum. The cells were treated with $1 \mu \mathrm{g} / \mathrm{mL}$ poly (I:C) for 1 hour and then incubated for 24 hours in a serum-free medium without poly (I:C). After collection, the cell-conditioned medium was passed through $0.22 \mu \mathrm{m}$ PVDF filters. Exosomes were isolated using Total Exosome Isolation Reagent (Invitrogen) according to the manufacturer's manual. Briefly, conditioned media were mixed with the reagent at a ratio of $2: 1$. The mixture was incubated at $4^{\circ} \mathrm{C}$ for 16 hours and centrifuged at $10000 \times \mathrm{g}$ for 1 hour at $4^{\circ} \mathrm{C}$. The pellets were resuspended in $250 \mu \mathrm{l}$ of $\mathrm{PBS}$, aliquoted and stored at $-80^{\circ} \mathrm{C}$ for further use.

\subsection{Exosome characterisation}

The amount of total protein in exosome samples was determined by Bradford assay (Sigma-Aldrich, Germany) measuring absorbtion of $\lambda=595 \mathrm{~nm}$ light in a Tecan Infinite 200 PRO plate reader. The exosomal markers tetraspanins CD63 and CD9 were quantified by ELISA kits (Abbexa CD63 ELISA Kit and Abbexa MRP1 ELISA Kit) according to the manufacturer's instructions.

The nanoparticle size distribution in isolated exosome preparations was determined by dynamic light scattering (ZetaSizer Nano ZS, Malvern PANalytical, UK). In short, $50 \mu \mathrm{l}$ of exosome preparation was homogenised for 5 minutes using $30 \mathrm{G}$ needle. Ten microliters of exosome preparation were mixed with $1990 \mu$ l of PBS in analytical cuvettes, monitored in the analyser, and the data were processed by ZetaSizer Nano software.

Exosome imaging was performed by transmission electron microscopy. Isolated exosomes were homogenised for 5 min with $30 \mathrm{G}$ needle and mixed with $4 \%$ paraformaldehyde at the ratio of 1:1. This solution was applied on carbon-coated Formvar copper meshes FCFT200-Cu-50 200 MESH (Sigma-Aldrich, Germany). The meshes were fixed in $1.7 \%$ glutaraldehyde solution for $5 \mathrm{~min}$, washed twice in deionised water for $2 \mathrm{~min}$ and stained with $2 \%$ uranyl acetate for $2 \mathrm{~min}$. After staining, the meshes were incubated with freshly prepared $2.25 \%$ methylcellulose and $2 \%$ uranyl acetate in a v/v ratio of $4: 1$ for 10 
min on an ice table. Prepared meshes were carefully dried on filter paper for 10 to $15 \mathrm{~min}$ and visualised using a transmission electron microscope Tecnai BioTwin Spirit G2 (FEI, Eindhoven, the Netherlands) on $80 \mathrm{kV}$ voltage. Electron microscope images were taken with a bottom-mounted 16 MP TEM CCD camera Eagle 4K employing TIA (FEI, Eindhoven, the Netherlands).

\subsection{Exosome labelling for in vitro and in vivo tracking}

Exosomes were labelled with Alexa Fluor 555 dye (BLOCK-it Alexa Fluor Red Fluorescent Control, Invitrogen) by lipofection (RNAiMAX, Invitrogen). Briefly, a mixture of $0.2 \mu \mathrm{M}$ of Alexa Fluor 555 dye was mixed with $3 \mu \mathrm{l}$ of RNAiMAX reagent in $100 \mu \mathrm{l}$ of the Opti-MEM ${ }^{\mathrm{TM}}$ medium (Thermo FischerScientific) and incubated for $5 \mathrm{~min}$ at room temperature. Exosome preparation $(1 \mathrm{mg} / \mathrm{mL}$ of total protein) was added into lipofection mixture and incubated at $37^{\circ} \mathrm{C}$ for one hour. After incubation, unincorporated dye and residual micelles were removed using Exosome spin columns (Invitrogen). Labelled exosomes were concentrated using $100 \mathrm{~K}$ Amicon ${ }^{\circledR}$ Ultra centrifugal filters (Millipore) and used for internalisation and tracking analysis.

\subsection{Intranasal in vivo administration of airway exosomes}

All experimental procedures were performed on 4-month-old Balb/c mice according to the Law of the Republic of Lithuanian Animal Welfare and Protection (License of the State Food and Veterinary Service for working with laboratory animals No. G2-96). The mice were maintained and handled at the Lithuanian University of Health Sciences animal house in agreement with the ARRIVE guidelines. Before the intranasal administration of fluorescently labelled exosomes, each nostril was treated with $100 \mathrm{U}$ hyaluronidase dissolved in $5 \mu \mathrm{l}$ PBS to increase the permeability of the mucus. After $30 \mathrm{~min}, 25 \mu \mathrm{l}$ of exosome solution containing $30 \mu \mathrm{g}$ of exosomal protein was introduced to each nostril (60 $\mu \mathrm{g}$ per mouse). The solution was administered gradually in $5 \mu \mathrm{l}$ portions followed by a 5 min interval and alternating the nostrils. After 1, 2, 3, and 5 hours, the mice were anaesthetised and sacrificed, and the brains were further processed for immunohistochemical analysis.

\subsection{In vitro exosome tracking and viability assessment}

For exosome uptake in vitro evaluation, Alexa Fluor 555-labelled exosome solution containing $0,5 \mathrm{mg} / \mathrm{mL}$ of total protein in PBS was applied on mixed glial and microglial cultures. After $20 \mathrm{~min}$ of incubation, Hoechst33342 (6 $\mu \mathrm{g} / \mathrm{mL}$, Thermo Fisher Scientific) was added to the incubation medium for visualisation of nuclei and isolectin GS-IB 4 from Griffonia simplificolia, Alexa Fluor ${ }^{\circledR} 488$ conjugate $(10 \mathrm{ng} / \mathrm{mL}$, Molecular Probes) for staining microglial with microglial and mixed glial using fluorescence microscope Zeiss Axio Observer.Z1 (Carl Zeiss, Jena, Germany).

The viability of microglial cells in pure microglial cultures after exosome uptake was assessed by double nuclear staining with fluorescent dyes Hoechst33342 $(6 \mu \mathrm{g} / \mathrm{mL})$ and propidium iodide $(3 \mu \mathrm{g} / \mathrm{mL})$ for $10 \mathrm{~min}$ and imaging in a fluorescent microscope Olympus IX71 (Olympus Corporation, Tokyo, Japan). The images were taken by a 01-Exi-AQA-R-FM-14-C camera (QImaging, Surrey, Canada) and the image analysis was performed by the ImageJ software.

\subsection{Immunohistochemistry of brain tissue}

Animal brains were rapidly removed, immediately washed in PBS and embedded in $4 \%$ paraformaldehyde solution for $30 \mathrm{~min}$. Afterwards, the brains were transferred to $25 \%$ sucrose and kept there for $24 \mathrm{~h}$ at $4{ }^{\circ} \mathrm{C}$. Then the tissue was frozen in liquid nitrogen and stored at $-80{ }^{\circ} \mathrm{C}$ until further processing. Next, serial coronal sections (20 $\mu \mathrm{m}$ thick) containing the substantia nigra were cut at $-23^{\circ} \mathrm{C}$ using a cryostat (HM 560 Microm, Walldorf, Germany). The sections were mounted on glass slides (Plus, Menzel Glaser), and the slides 
were allowed for complete dehydration in the cryostat chamber for $10 \mathrm{~min}$. The slides were washed with PBS solution ( $3 \times 10 \mathrm{~min}$ ) and subjected to $0.5 \%$ Triton X-100 permeabilisation for 40-60 minutes at room temperature in a dark, humid environment. The slides were then washed with PBS ( $3 \times 10 \mathrm{~min}$ ) and incubated overnight with $1 \mu \mathrm{g} / \mathrm{mL}$ primary rabbit monoclonal antibodies against microglial transmembrane protein TMEM119 (RRID:AB_2800343, ab209064, Abcam) overnight at $4^{\circ} \mathrm{C}$. After 3 × 10 min washing with PBS, the slides were incubated with AlexaFluor ${ }^{\circledR} 488$ conjugated chicken anti-rabbit IgG (Thermo Fisher Scientific) secondary antibodies diluted in PBS 1:200 for 2 hours at room temperature, in a dark and humid environment. The slides were then rewashed with PBS ( $3 \times 10 \mathrm{~min}$ ) and coated with anti-fading oil (Vectashield, Vector Laboratories), the edges varnished with colourless nail polish. For negative control, only PBS solution was added instead of primary antibodies, followed by secondary antibodies. The stained tissue was visualised by laser scanning confocal microscope: Zeiss Axio Observer LSM 700 (Carl Zeiss Microimaging Inc., Jena, Germany).

\subsection{Evaluation of intracellular and intramitochondrial ROS}

Cytoplasmic and intramitochondrial ROS were evaluated as described in [27]. Briefly, the 2', 7'-dichlorofluorescein diacetate (DCFDA, Invitrogen) was used to assess the formation of intracellular ROS in microglia. Microglial cells were seeded in 96-well plates (50 000 / well) and cultivated for $24 \mathrm{~h}$. After incubation, cells were treated with poly (I:C)primed and not primed airway cell exosomes $(10 \mu \mathrm{g} / \mathrm{ml}$ of total protein) for $16-18 \mathrm{~h}$. After incubation, all cells were washed with Hank's Balanced Salt Solution (HBSS, Gibco). Following washes, cells were stained with $10 \mu \mathrm{M}$ DCFDA for $30 \mathrm{~min}$ at $37^{\circ} \mathrm{C}$, repeatedly washed with HBSS and visualised using Olympus IX2-ILL100 fluorescence microscope (Olympus, Japan). To evaluate mitochondrial superoxide, the cells were grown in clear 96well plates the same way as for cytoplasmic ROS assessment. The cells were 3x washed with HBSS and incubated with $2 \mu \mathrm{M}$ MitoSoxTM Red (Thermo Fisher Scientific) in HBSS at $37^{\circ} \mathrm{C}$ in the dark for $15 \mathrm{~min}$. The images were taken by fluorescent microscope Zeiss Axio Observer.Z1, and fluorescence intensity was evaluated by ImageJ software.

\subsection{Statistical analysis}

Statistical analysis was performed using Sigma Plot v12.5 software. The means of the experimental data are presented with standard errors. Statistical comparisons of the two groups were performed using Student's t-test. Multiple groups were compared using and one-way analysis of variance (ONE WAY ANOVA) with Bonferroni statistical criterion. Differences between means were considered statistically significant at $\mathrm{p}<0.05$.

\section{Results}

\subsection{Identification and characterisation of airway cell exosomes}

At first, exosomes isolated from poly (I:C)-primed and not primed rat airway cellconditioned medium were evaluated for morphology by transmission electron microscopy (TEM). The samples contained vesicles of approximately $10-190 \mathrm{~nm}$ in diameter (Figure 2a,b). 


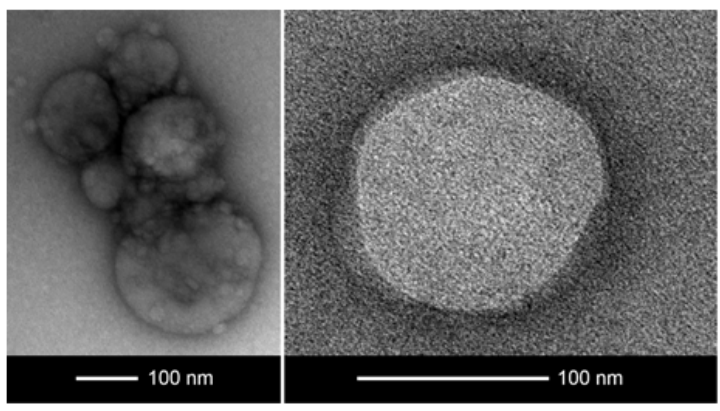

(a)

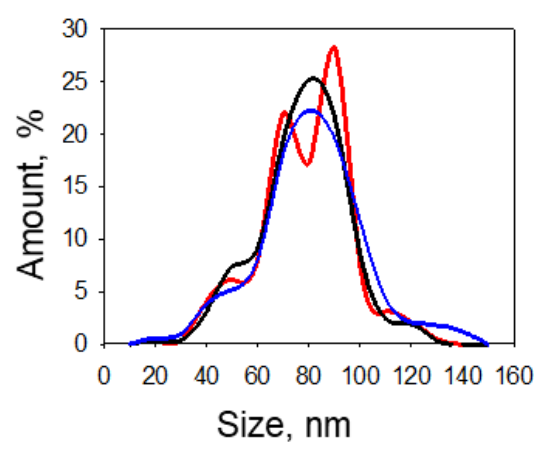

(b)

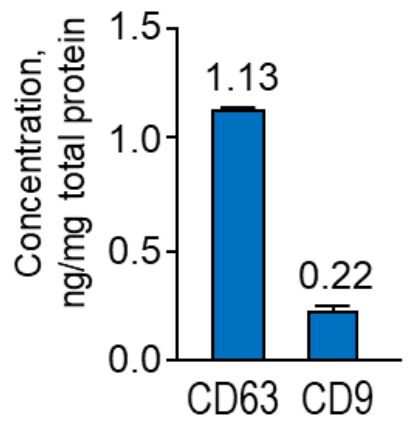

(c)

Figure 2. Poly (I:C)-treated rat airway cell exosome morphology, particle size distribution and specific markers. Representative transmission electron microscopy images (a), dynamic ligh scattering nanoparticle analysis data of three samples (b) and tetraspanin CD63 and CD9 content per total exosome preparation protein determined by ELISA.

The dynamic light scattering analysis revealed that the particle diameter in exosome samples ranged from 10 to $160 \mathrm{~nm}$, and 98 per cent of the particles in the samples were in the range of 30-150 nm, which is characteristic for exosomes (Figure 2c). Next, exosome preparations were ELISA-tested for common exosomal markers, tetraspanins CD9 and CD63. The analysis confirmed both markers present in the samples; however, CD63 was found about five times more than CD9 (Figure 2d). Similar characteristics were found by examining exosome preparations from mice airway cell cultures (Figure A1). There were no detectable differences in morphology, size distribution and CD63/CD9 presence found between poly (I:C)-primed and not primed airway cell exosomes (data not shown).

\subsection{Poly (I:C)-primed airway exosome tracking in brain and microglia}

For blood-brain barrier penetration monitoring, Alexa Fluor-555 (AF555) labelled exosomes from poly (I:C)-primed airway cells were applied on microglial cell cultures and introduced intranasally to mice. Red fluorescence became visible in the brain already 1 hour after treatment, and later (after 3 and 5 hours), the fluorescence spots became more extensive (Figure 3a). Some of them resembled cell body shape suggesting that exosomes were internalised by specific cells at this time point. Interestingly, some brain regions, such as the hippocampal pyramidal neuron layer, were more prone to collect exosomes (Figure $3 b)$. There was no red staining visible in brain slices from mice that did not receive exosome treatment (Oh image in Fig. 3a).

Next, the brain slices were immunostained for TMEM19 to determine if the exosomes were internalised by microglial cells. The staining revealed that most exosomes colocalised with microglial cell bodies or their processes (Figure 4a), indicating that microglia indeed uptake exosomes after entering the brain. In vitro experiments on cultivated rat pure microglia and mixed glia where microglial cells grow on top of astrocytes confirmed that microglia cells internalise exosomes more rapidly than others. All exosomes were entirely relocated to microglial cells 30 minutes after addition to the culture medium in both pure microglial and mixed glial cultures (Figure $4 \mathrm{~b}$ ). The exosomes looked like they collected into cytoplasmic vesicles suggesting that the uptake pathway was either endocytosis, phagocytosis, or micropinocytosis. Such exosome internalisation did not affect the viability of microglial cells; double nuclear fluorescent staining with Hoechst33342 and propidium iodide revealed no significant difference in viable cell number between exosome-treated and untreated, as well as between poly (I:C)primed and not primed airway exosome-treated microglial cultures; the percentage of viable cells in all cultures were above $98 \%$ (Figure A2). 

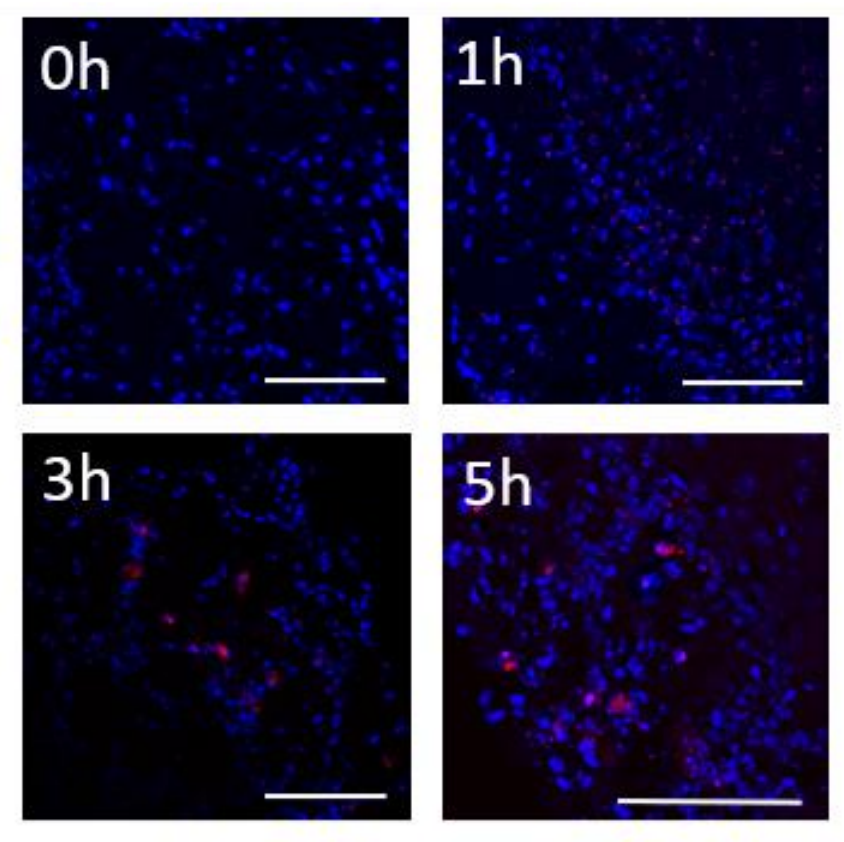

(a)

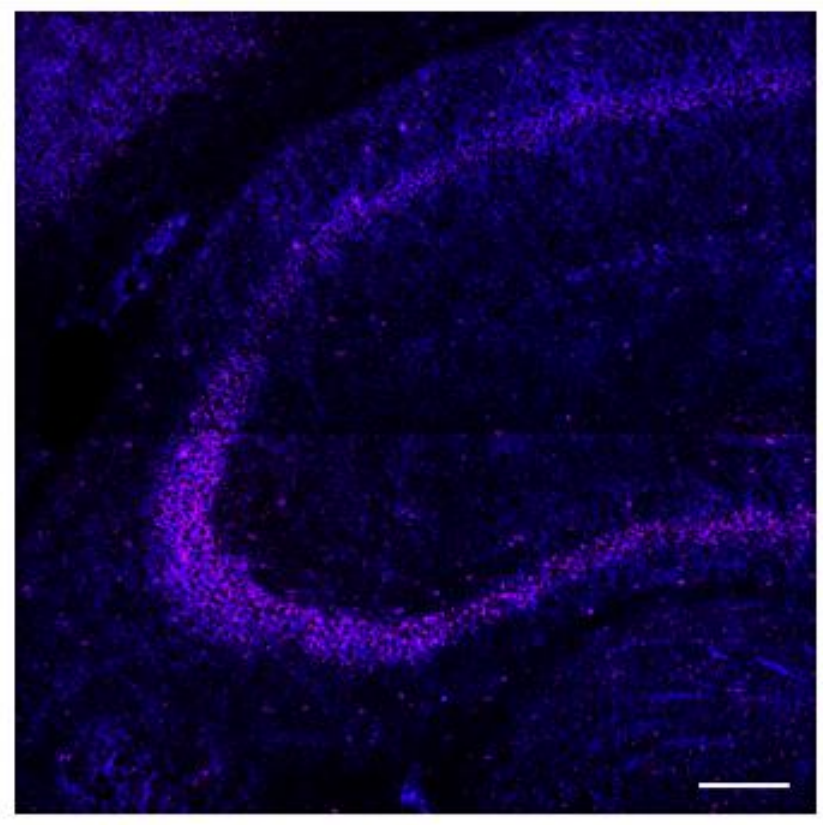

(b)

Figure 3. Exosomes from poly (I:C)-treated airway cells in mouse brain sections after 0, 1, 3, and 5 hours following intranasal introduction (a). In (b) - exosomes in mouse hippocampus 1 hour after introduction. Exosomes loaded with RNR-conjugated AF555 are red, and nuclei are stained blue with DAPI. Scale bar $100 \mu \mathrm{m}$. 
EGZOSOMES
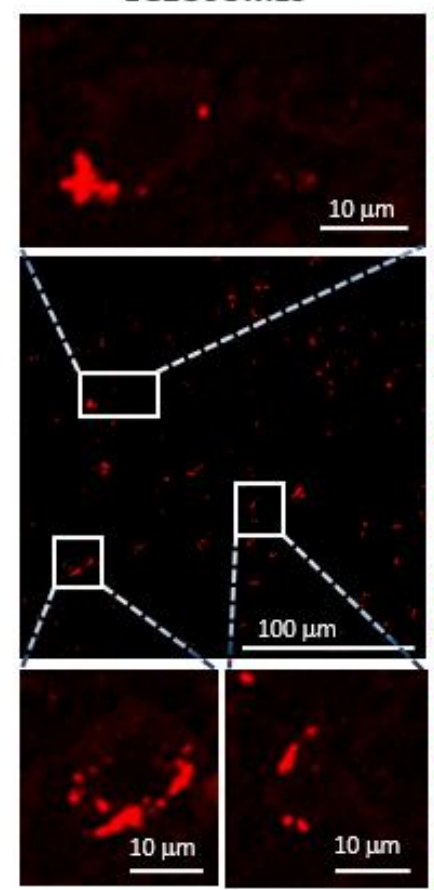

HTHFIELD

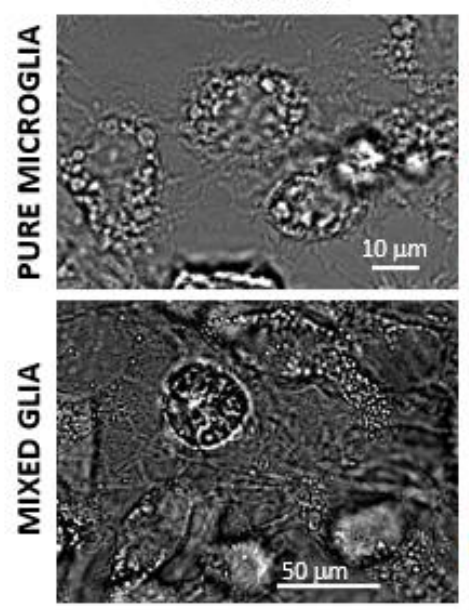

MICROGLIA

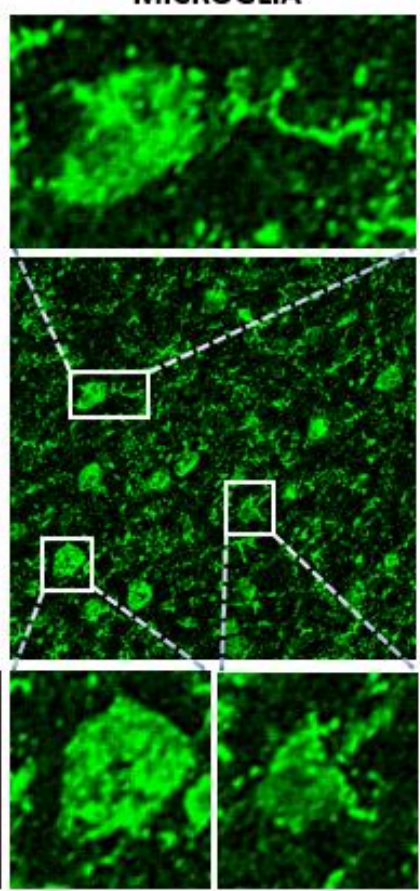

NUCLEI
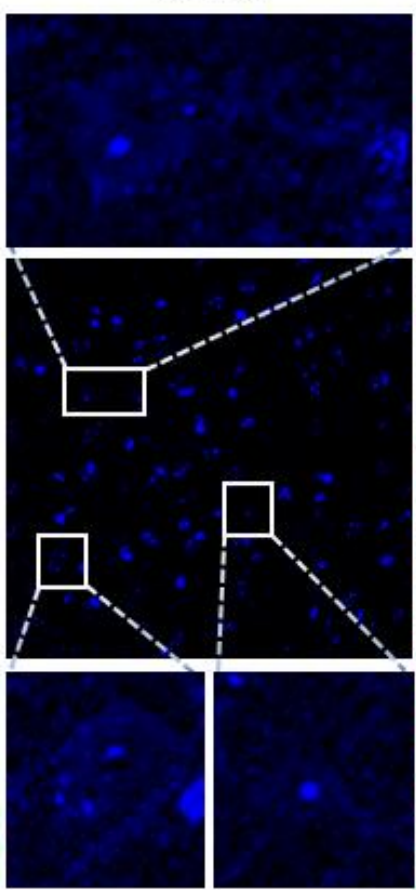

(a)

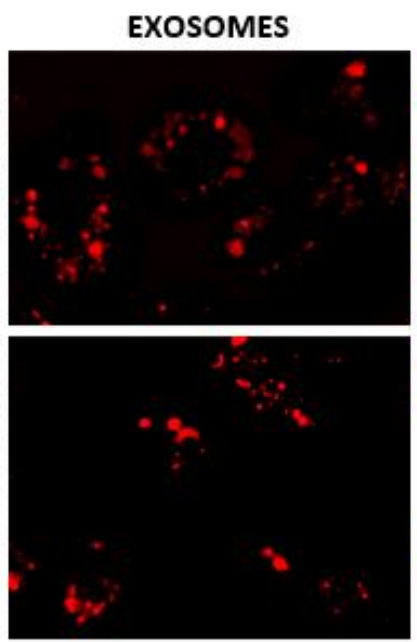

MICROGLIA
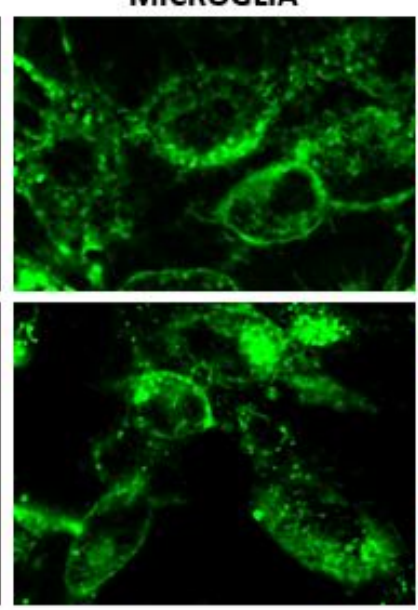

MERGED

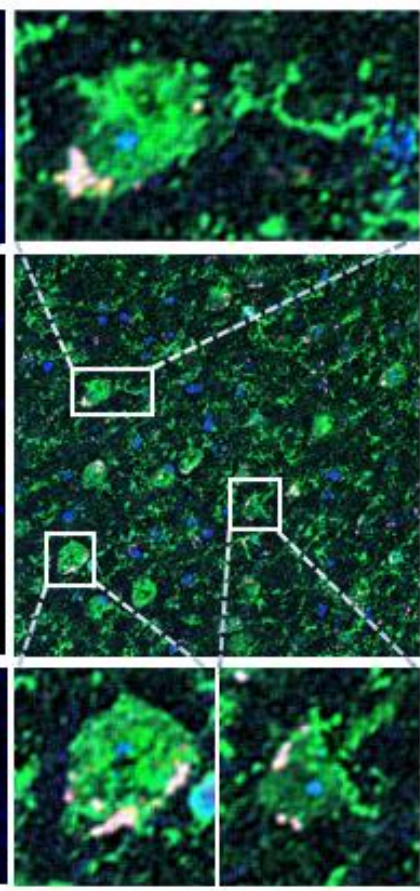

MERGED

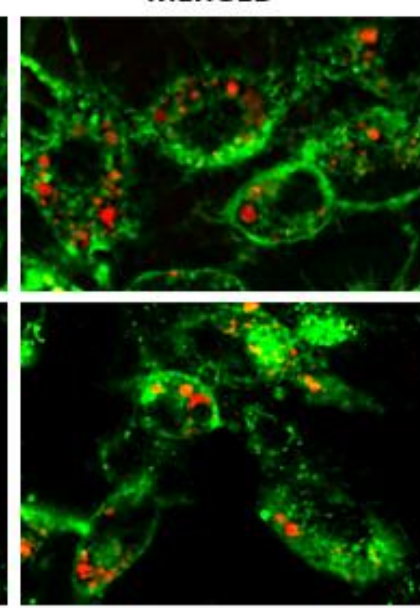

(b)

Figure 4. Poly (I:C)-treated airway cell exosome internalisation by microglia in mouse brain 2 hours after intranasal introduction (a) and in cultivated rat glial cultures $30 \mathrm{~min}$ after treatment (b). Exosomes loaded with RNR-conjugated AF555 are red, nuclei are stained blue with DAPI (in a) or Hoechst33342 (in b). Microglial cells are green visualised by immunostaining against TMEM119 (in a) or affinity staining with isolectin $\mathrm{B}_{4}$ (in b).

\subsection{Poly (I:C)-primed airway cell exosome impact on ROS formation in microglia}

Mitochondrial and cytoplasmic ROS act upstream of the inflammatory cascade during viral infection and play a crucial role in immune memory formation [28-30]. To determine whether poly (I:C)-primed airway exosomes affect mitochondrial and cytoplasmic ROS production, microglial cells were incubated with the exosomes for 16-18 hours, loaded with either MitoSOX ${ }^{\mathrm{TM}}$ or DCFDA and monitored under a fluorescent microscope. Both visual monitoring and quantitative evaluation of the micrographs revealed that poly (I:C)-stimulated airway cell exosomes significantly increased the 
formation of mitochondrial ROS in microglial cells (Figure 5a). After 24 hours, the MitoSOX ${ }^{\mathrm{TM}}$ fluorescence intensity was by $31 \%$ higher compared to the samples treated with untreated airway cell exosomes. Moreover, the increased level of mitochondrial ROS in poly (I:C)-primed airway cell exosome-treated samples remained even after 48 hours after the treatment. Additionally, exosomes from poly (I:C)-primed airway cells significantly increased the formation of cytoplasmic ROS in microglia; the DCFDA fluorescence level after 24 hours post-treatment rose by $14 \%$ (Figure 5b). There was no significant difference in MitoSOX ${ }^{\mathrm{TM}}$ and DCFDA fluorescence intensity between untreated control (100\%) and samples treated with exosomes from airway cells unaffected by poly (I:C).

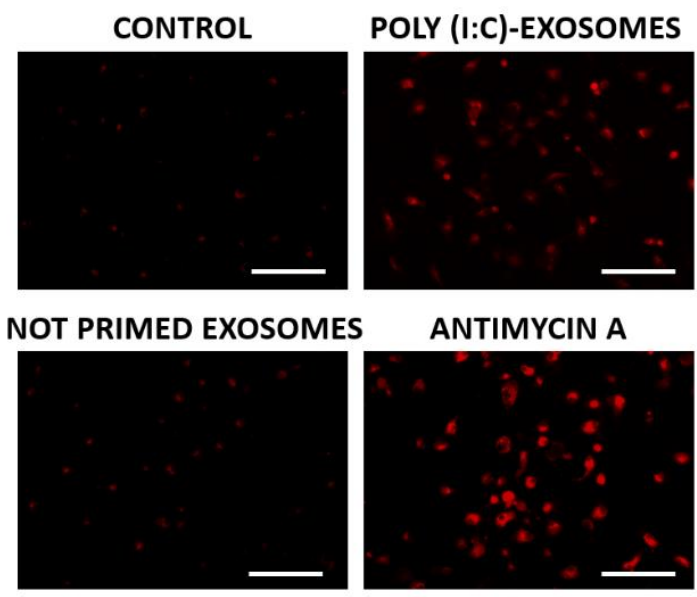

MITOCHONDRIAL ROS

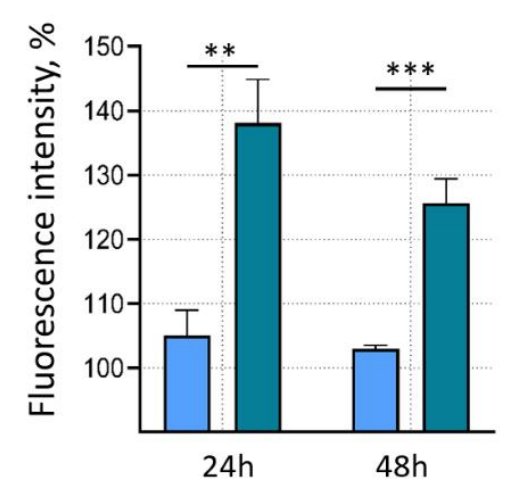

(a)

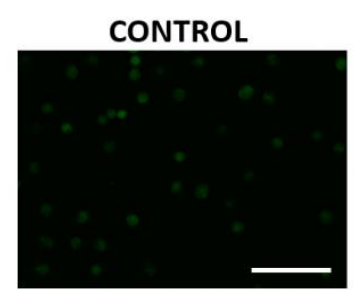

POLY (I:C )-EXOSOMES
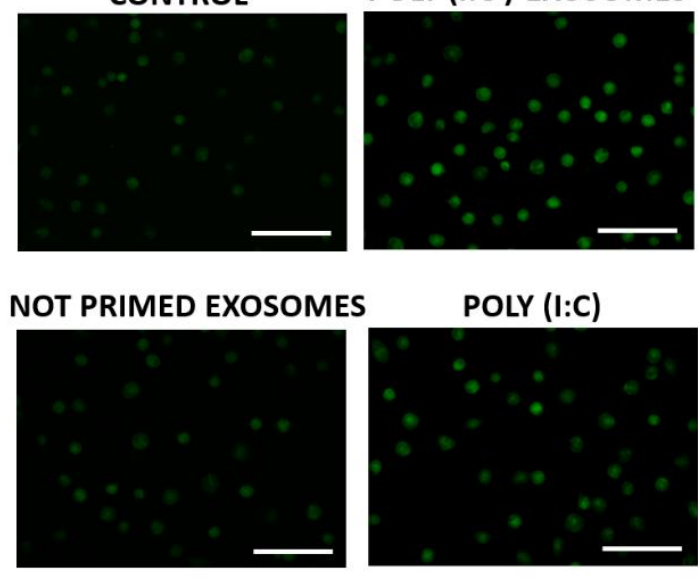

Untreated airway exosomes

Poly (I:C)-treated airway exosomes

\section{CYTOPLASMIC ROS}

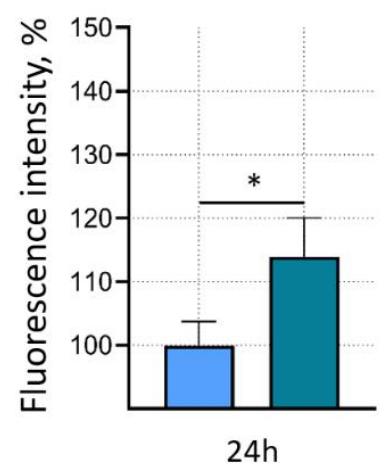

(b)

Figure 5. Intramitochondrial and cytoplasmic reactive oxygen species (ROS) formation in microglia after treatment with exosomes from poly (I:C)-primed airway cells. Cytoplasmic ROS were detected by DCFDA assay and mitochondrial superoxide - by MitoSOX ${ }^{\mathrm{TM}}$ fluorescence. (a) - representative images and quantitative evaluation of MitoSOX fluorescence in cultured microglia. For positive control of the assay, $100 \mu \mathrm{M}$ Antimycin A was used. Scale bar is $100 \mu \mathrm{m}$. (b) - representative images and quantitative evaluation of 2,7-dichlorofluorescein (derived from DCFDA) fluorescence in microglial cultures. For positive control of the assay, $1 \mu \mathrm{g} / \mathrm{mL}$ poly (I:C) was used. Scale bar is $100 \mu \mathrm{m}$. The quantitative data of ROS-dependent fluorescence intensity in micrographs are presented as percentage of untreated control and expressed as averages \pm standard deviation of 3 experiments in 3 biological replicates. ${ }^{* * *}$ indicates statistically significant difference when $\mathrm{p}<0.001 ;{ }^{* *}-\mathrm{p}<0.01 ;^{*}-\mathrm{p}<0.05$.

\section{Discussion}


The main highlights of the present study include confirmation that (1) airway cell exosomes easily penetrate the blood-brain barrier of healthy laboratory mice and (2) are quickly (within an hour or two) internalised by microglial cells. Moreover, (3) the exosomes from airway cells that received viral infection mimicking priming induce specific changes in microglial cells, leading to increased intracellular and intramitochondrial ROS generation.

Upper respiratory tract infections result in 10 million outpatient visits per year, and $70-90 \%$ of these infections are of viral origin [31,32]. Viral infections promote innate or non-specific and acquired or specific immune responses. There is a well-established correlation between peripheral viral infection and neuroinflammation that might lead to neurodegeneration [33,34]. The recently emerged SARS-CoV-2 virus that caused COVID-19 pandemia is also not an exception from this point of view; there are numerous reports about neuroinflammation-related central nervous system damage caused by this infection [35]. However, the mechanisms transmitting inflammation from the periphery to the brain remains elusive.

One of the most suggestable candidates for inflammation transmission from the periphery to the brain is exosomes. Exosomes of cells affected by bacteria, viruses, parasites, or fungi contain pathogen components that can be transferred to other cells [36]. Exosomes produced by bacterial infection-affected macrophages contain proinflammatory factors that activate $B$ and $T$ lymphocytes enhancing the immune response $[37,38]$. Virus-treated cells contain viral proteins and RNA that cause inflammatory response or even infection in recipient cells [36]. Herpes simplex, hepatitis A, B, C, and human immunodeficiency (HIV) viruses spread through exosomes [39-42]. The above-listed evidence allows assuming that some of the exosomes produced by infected cells could penetrate the central nervous system and cause neuroinflammation. Although several studies report peripheral exosomes crossing the blood-brain barrier [41,42], their further cellular uptake remained unknown. In addition, none of the examined exosomes originated from airway epithelium or fibroblasts. Our study experimentally demonstrated fast brain uptake of airway epithelial exosomes and provided evidence about their localisation in microglial cells. In addition, the in vivo data were supported by in vitro experimental proof of much faster exosome uptake performance by microglia compared to astrocytes. Although this is not direct evidence of airway infection spreading to the brain, the study gives a solid reason and background for studying this possibility. Interestingly, there were visually more airway cell exosomes in the pyramidal neuron area of the hippocampus after intranasal introduction. Hippocampal neurons are the primary target of Alzheimer's disease, and the cause of such selective damage to this area remains unknown. The fact that the hippocampus selectively collects peripheral exosomes carrying inflammatory mediators suggests a new hypothesis for Alzheimer's disease development. The hippocampus and olfactory regions are anatomically close; they are connected by memory formation networks and participate in glymphatic brain clearance $[44,45]$. Such anatomical and functional relations likely favour exosome transmission from the nasal cavity. Similarly to our findings, microglial localisation of intravenously injected fluorescently labelled exosomes was observed by Li and colleagues [43]. The authors have found that exosomes from serum of LPS-treated mice initiate inflammation in the brains of healthy exosome recipients. Such results strongly suggest that peripheral exosomes might be important yet underestimated players in neuroinflammation.

This study demonstrated that exosomes from virus mimetic-treated airway cells stimulate ROS generation in cultivated microglia. We have applied two different assays for ROS evaluation. Conversion of DCFDA to fluorescent 2,7-dichlorofluorescein (DCF) indicates hydroxyl, peroxyl and some other species produced into cell cytoplasm [46]. Mitochondrially targeted MitoSOX ${ }^{\mathrm{TM}}$ Red, in its turn, reports about the intensity of generation of superoxide radicals within mitochondria. Of all ROS, the respiratory chain primarily produces superoxide, which cannot cross membranes and remains where made unless converted to hydrogen peroxide by superoxide dismutase. Hydrogen peroxide molecules penetrate mitochondrial membranes to the cytosol, where it often undergoes further 
conversions depending on the chemical environment, e.g., to hydroxyl radical by Fenton reaction. Thus, mitochondrial superoxide could also be the source of cytoplasmic ROS detected by the DCFDA reaction. The fact that poly (I:C)-primed airway exosomes stimulated mitochondrial superoxide generation far more intensively than intracellular (cytoplasmic) ROS strongly suggests mitochondria were the primary source of radicals in this case. However, to prove this hypothesis, more experimental evidence is required, such as testing how microglial cytoplasmic ROS levels induced by poly (I:C)-primed airway exosomes would be affected by the presence of mitochondrial superoxide scavenger mitoTEMPO.

Reactive oxygen species, including those from mitochondria, are generated as a fast response to infection [28,47]. Mitochondrial ROS lie at the top of the innate immune response cascade and precedes ROS generation from phagocytosis-related NADPH oxidase [48]. Moreover, they are required for virus-induced mitochondrial antiviral signalling protein (MAVS) to activate inflammasome [49,50], which is directly linked to neurodegeneration according to recent research [51,52]. Such an important role of mitochondrial ROS in inflammatory response indicate the following landmarks in dissecting the role of virusprimed airway cell exosomes, such as examining their effect on the mitochondrial and glycolytic profile of microglial cells inflammatory cytokine expression and secretion, inflammasome activation and impact on the inflammatory level in the brain. Also, elucidating the mechanism of exosome crossing the blood-brain barrier under the ordinary and infection-affected conditions and identifying the virus-induced molecular profile of airway cell exosomes would be of great importance in understanding the role of these extracellular vesicles in communication between the periphery and brain during viral infections.

\section{Conclusions}

- Virus mimetic poly (I:C)-primed and not primed airway cell exosomes reach brain tissue after not more than an hour from the intranasal introduction in mice.

- Both in the brain and culture, airway cell exosomes are internalised mainly by microglial cells.

- In pure microglial and mixed glial cultures, poly (I:C)-primed and not primed airway cell exosomes relocate from the extracellular medium to microglia within $30 \mathrm{~min}$. During this period, the exosomes are not taken up by astrocytes.

- Airway exosome uptake does not influence the viability of microglial cells.

- Poly (I:C)-primed airway exosomes induce a significant and lasting increase in cytoplasmic and intramitochondrial ROS production. Conversely, the exosomes from not primed airway cells do not cause changes in ROS levels.

Author Contributions: Conceptualisation, L.J., R.M. and A.J.; methodology, D.K., L.J., N.P., Z.M., Z.B., and A.J.; formal analysis, D.K., O.J., L.J., H.I., and I.S.; investigation, D.K., D.N., O.J., L.J., A.M., N.P., J.S., H.I., Z.M. and I.S.; writing - original draft preparation, D.G. and A.J.; writing-review and editing, D.G., N.P., R.M., D.H.P. and A.J.; visualisation, D.K. and D.G.; supervision, D.H.P., R.M. and A.J. All authors have read and agreed to the published version of the manuscript.

Funding: The study is a part of the EXOTARGET project funded by a grant No. 01.2.2-LMT-K-71801-0036 from the Research Council of Lithuania.

Institutional Review Board Statement: The study was conducted according to the guidelines of the Declaration of Helsinki, and approved by the Lithuanian Food and Veterinary Service (protocol code G2-96, 2018, $14^{\text {th }}$ of November).

Data Availability Statement: The raw data supporting the conclusions of this manuscript will be made available by the authors, without undue reservation, to any qualified researcher.

Conflicts of Interest: The authors declare no conflict of interest. 


\section{Appendix A}

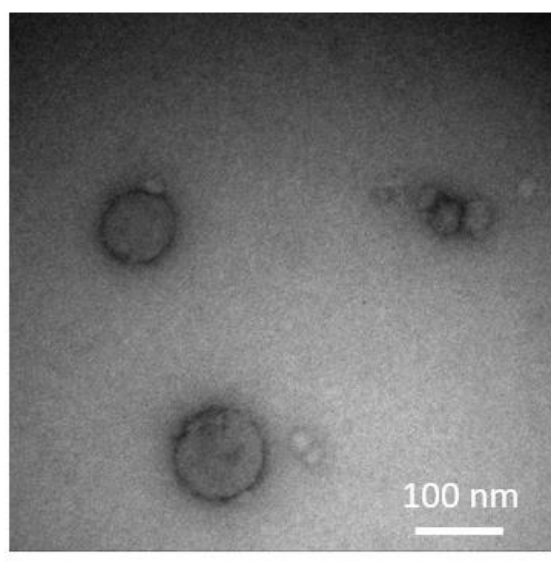

(a)

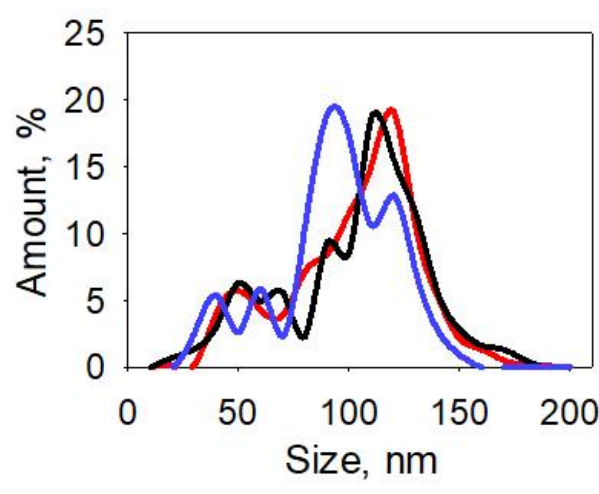

(b)

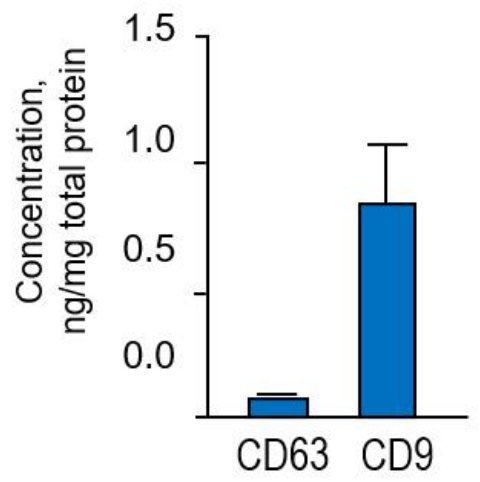

(c)

Figure A1. Characterisation of mouse airway exosomes. A representative electron microscopy image (a), particle size and amount distribution (b), and evaluation of specific protein markers CD9 and CD63 (c).

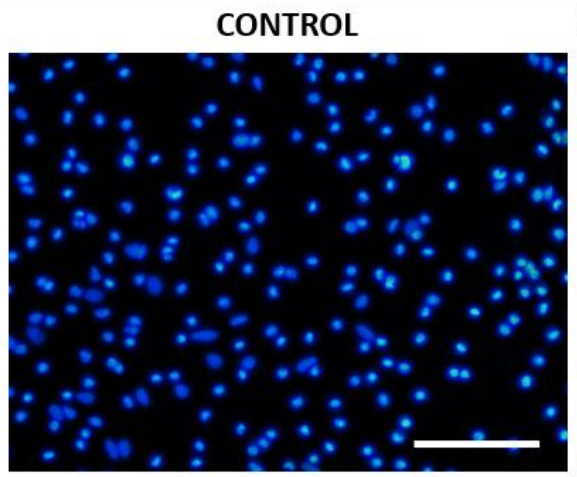

\section{POLY (I:C)-PRIMED AIRWAY EXOSOMES}

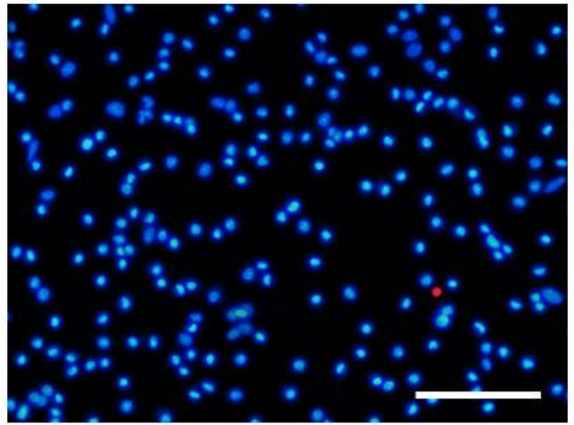

UNTREATED AIRWAY EXOSOMES

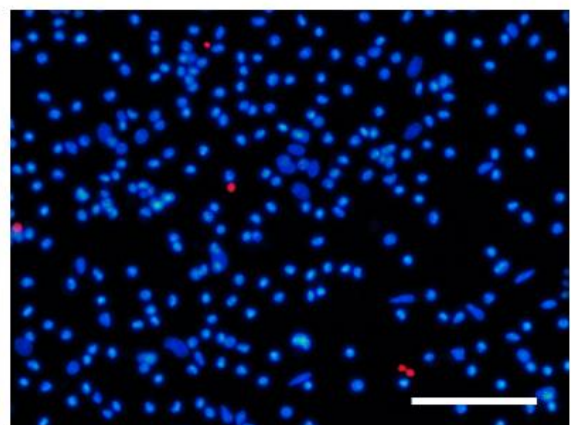

Figure A2. Representative images of viability evaluation of airway exosome-treated microglial cultures. The cells were stained with Hoechst33342 to visualise all nuclei blue and with propidium iodide to detect dying cells with lost plasma membrane integrity (red fluorescence of the nuclei).

\section{References}

1. Goody, M.F.; Sullivan, C.; Kim, C.H. Studying the immune response to human viral infections using zebrafish. Dev. Comp. Immunol. 2014, 46, 84-95.

2. Mackie, P.L. The classification of viruses infecting the respiratory tract. Paediatr. Respir. Rev. 2003, 4, 84-90.

3. Chahar, H.S.; Corsello, T.; Kudlicki, A.S.; Komaravelli, N.; Casola, A. Respiratory Syncytial Virus Infection Changes Cargo Composition of Exosome Released from Airway Epithelial Cells. Sci. Rep. 2018, 8, 387, doi:10.1038/s41598-017-18672-5.

4. Hassanpour, M.; Rezaie, J.; Nouri, M.; Panahi, Y. The role of extracellular vesicles in COVID-19 virus infection. Infect. Genet. Evol. 2020, 85, 104422.

5. Gunasekaran, M.; Bansal, S.; Ravichandran, R.; Sharma, M.; Perincheri, S.; Rodriguez, F.; Hachem, R.; Fisher, C.E.; Limaye, A.P.; Omar, A.; et al. Respiratory viral infection in lung transplantation induces exosomes that trigger chronic rejection. J. Hear. Lung Transplant. 2020, 39, 379-388, doi:10.1016/j.healun.2019.12.009.

6. Zomer, A.; Vendrig, T.; Hopmans, E.S.; van Eijndhoven, M.; Middeldorp, J.M.; Pegtel, D.M. Exosomes. Commun. Integr. Biol. 2010, 3, 447-450, doi:10.4161/cib.3.5.12339.

7. Exosomes: biogenesis, biologic function and clinical potential Available online: https://www.ncbi.nlm.nih.gov/pmc/articles/PMC6377728/ (accessed on Feb 14, 2020).

8. Keerthikumar, S.; Chisanga, D.; Ariyaratne, D.; Al Saffar, H.; Anand, S.; Zhao, K.; Samuel, M.; Pathan, M.; Jois, M.; Chilamkurti, N.; et al. ExoCarta: A Web-Based Compendium of Exosomal Cargo. J. Mol. Biol. 2016, 428, 688-692, doi:10.1016/j.jmb.2015.09.019. 
9. Rajagopal, C.; Harikumar, K.B. The origin and functions of exosomes in cancer. Front. Oncol. 2018, 8, 66.

10. Xu, M.Y.; Ye, Z.S.; Song, X.T.; Huang, R.C. Differences in the cargos and functions of exosomes derived from six cardiac cell types: A systematic review. Stem Cell Res. Ther. 2019, 10, 1-11.

11. Flanagan, J.; Middeldorp, J.; Sculley, T. Localization of the Epstein-Barr virus protein LMP 1 to exosomes. J. Gen. Virol. 2003, 84, 1871-1879, doi:10.1099/vir.0.18944-0.

12. Narayanan, A.; Iordanskiy, S.; Das, R.; Van Duyne, R.; Santos, S.; Jaworski, E.; Guendel, I.; Sampey, G.; Dalby, E.; IglesiasUssel, M.; et al. Exosomes derived from HIV-1-infected cells contain trans-activation response element RNA. J. Biol. Chem. 2013, 288, 20014-20033, doi:10.1074/jbc.M112.438895.

13. Choi, H.; Lee, H.; Kim, S.R.; Gho, Y.S.; Lee, S.K. Epstein-Barr Virus-Encoded MicroRNA BART15-3p Promotes Cell Apoptosis Partially by Targeting BRUCE. J. Virol. 2013, 87, 8135-8144, doi:10.1128/jvi.03159-12.

14. Pegtel, D.M.; Cosmopoulos, K.; Thorley-Lawson, D.A.; Van Eijndhoven, M.A.J.; Hopmans, E.S.; Lindenberg, J.L.; De Gruijl, T.D.; Würdinger, T.; Middeldorp, J.M. Functional delivery of viral miRNAs via exosomes. Proc. Natl. Acad. Sci. U. S. A. 2010, 107, 6328-6333, doi:10.1073/pnas.0914843107.

15. Haneklaus, M.; Gerlic, M.; Kurowska-Stolarska, M.; Rainey, A.-A.; Pich, D.; McInnes, I.B.; Hammerschmidt, W.; O'Neill, L.A.J.; Masters, S.L. Cutting Edge: miR-223 and EBV miR-BART15 Regulate the NLRP3 Inflammasome and IL-1 $\beta$ Production. J. Immunol. 2012, 189, 3795-3799, doi:10.4049/jimmunol.1200312.

16. Banks, W.A.; Sharma, P.; Bullock, K.M.; Hansen, K.M.; Ludwig, N.; Whiteside, T.L. Transport of extracellular vesicles across the blood-brain barrier: Brain pharmacokinetics and effects of inflammation. Int. J. Mol. Sci. 2020, 21, 1-21, doi:10.3390/ijms21124407.

17. Alvarez-Erviti, L.; Seow, Y.; Yin, H.; Betts, C.; Lakhal, S.; Wood, M.J.A. Delivery of siRNA to the mouse brain by systemic injection of targeted exosomes. Nat. Biotechnol. 2011, 29, 341-345, doi:10.1038/nbt.1807.

18. Li, Q.; Barres, B.A. Microglia and macrophages in brain homeostasis and disease. Nat. Rev. Immunol. 2018, 18, $225-242$.

19. Aguzzi, A.; Barres, B.A.; Bennett, M.L. Microglia: Scapegoat, saboteur, or something else? Science (80-. ). $2013,339,156-161$.

20. Paolicelli, R.C.; Bolasco, G.; Pagani, F.; Maggi, L.; Scianni, M.; Panzanelli, P.; Giustetto, M.; Ferreira, T.A.; Guiducci, E.; Dumas, L.; et al. Synaptic pruning by microglia is necessary for normal brain development. Science (80-. ). 2011, 333, 1456-1458, doi:10.1126/science.1202529.

21. Fu, R.; Shen, Q.; Xu, P.; Luo, J.J.; Tang, Y. Phagocytosis of microglia in the central nervous system diseases. Mol. Neurobiol. 2014, 49, 1422-1434, doi:10.1007/s12035-013-8620-6.

22. Brown, G.C.; Neher, J.J. Microglial phagocytosis of live neurons. Nat. Rev. Neurosci. 2014, 15, 209-216, doi:10.1038/nrn3710.

23. Ransohoff, R.M. How neuroinflammation contributes to neurodegeneration. Science (80-. ). 2016, 353, 777-783.

24. Wendeln, A.-C.; Degenhardt, K.; Kaurani, L.; Gertig, M.; Ulas, T.; Jain, G.; Wagner, J.; Häsler, L.M.; Wild, K.; Skodras, A.; et al. Innate immune memory in the brain shapes neurological disease hallmarks. Nature 2018, 556, 332-338, doi:10.1038/s41586-018-0023-4.

25. Weinberg, S.E.; Sena, L.A.; Chandel, N.S. Mitochondria in the Regulation of Innate and Adaptive Immunity. Immunity 2015, 42, 406-417, doi:10.1016/j.immuni.2015.02.002.

26. Balion, Z.; Cèpla, V.; Svirskiene, N.; Svirskis, G.; Druceikaitė, K.; Inokaitis, H.; Rusteikaitė, J.; Masilionis, I.; Stankevičienè, G.; Jelinskas, T.; et al. Cerebellar cells self-assemble into functional organoids on synthetic, chemically crosslinked ECMmimicking peptide hydrogels. Biomolecules 2020, 10, 754, doi:10.3390/biom10050754.

27. Dematteis, G.; Vydmantaite, G.; Ruffinatti, F.A.; Chahin, M.; Farruggio, S.; Barberis, E.; Ferrari, E.; Marengo, E.; Distasi, C.; Morkūnienè, R.; et al. Proteomic analysis links alterations of bioenergetics, mitochondria-ER interactions and proteostasis in hippocampal astrocytes from 3xTg-AD mice. Cell Death Dis. 2020, 11, 1-16, doi:10.1038/s41419-020-02911-1.

28. West, A.P.; Shadel, G.S.; Ghosh, S. Mitochondria in innate immune responses. Nat. Rev. Immunol. $2011,11,389-402$.

29. Kim, H.J.; Kim, C.H.; Ryu, J.H.; Kim, M.J.; Park, C.Y.; Lee, J.M.; Holtzman, M.J.; Yoon, J.H. Reactive oxygen species induce antiviral innate immune response through IFN- $\lambda$ regulation in human nasal epithelial cells. Am. J. Respir. Cell Mol. Biol. 2013, 49, 855-865, doi:10.1165/rcmb.2013-0003OC.

30. Kim, S.; Kim, M.J.; Park, D.Y.; Chung, H.J.; Kim, C.H.; Yoon, J.H.; Kim, H.J. Mitochondrial reactive oxygen species modulate innate immune response to influenza A virus in human nasal epithelium. Antiviral Res. 2015, 119, 78-83, doi:10.1016/j.antiviral.2015.04.011.

31. Meneghetti, A. Upper Respiratory Tract Infection Medication. Medscape 2015, 1-18.

32. Eugenia, M.; Patricia, D.; Horacio, L.; Ocadiz-Delgado, R.; Cabello-Gutierrez, C. Pathogenesis of Viral Respiratory Infection. In Respiratory Disease and Infection - A New Insight; InTech, 2013.

33. Steel, A.J.; Eslick, G.D. Herpes viruses increase the risk of Alzheimer's disease: A meta-analysis. J. Alzheimer's Dis. 2015, 47, 351-364, doi:10.3233/JAD-140822.

34. Klein, R.S.; Garber, C.; Funk, K.E.; Salimi, H.; Soung, A.; Kanmogne, M.; Manivasagam, S.; Agner, S.; Cain, M. Neuroinflammation During RNA Viral Infections. Annu. Rev. Immunol. 2019, 37, 73-95.

35. Amruta, N.; Chastain, W.H.; Paz, M.; Solch, R.J.; Murray-Brown, I.C.; Befeler, J.B.; Gressett, T.E.; Longo, M.T.; EnglerChiurazzi, E.B.; Bix, G. SARS-CoV-2 mediated neuroinflammation and the impact of COVID-19 in neurological disorders. Cytokine Growth Factor Rev. 2021, 58, 1-15.

36. Schorey, J.S.; Cheng, Y.; Singh, P.P.; Smith, V.L. Exosomes and other extracellular vesicles in host-pathogen interactions. EMBO Rep. 2015, 16, 24-43, doi:10.15252/embr.201439363. 
37. Quah, B.J.C.; O’Neill, H.C. Mycoplasma contaminants present in exosome preparations induce polyclonal B cell responses . J. Leukoc. Biol. 2007, 82, 1070-1082, doi:10.1189/jlb.0507277.

38. Bhatnagar, S.; Schorey, J.S. Exosomes released from infected macrophages contain Mycobacterium avium glycopeptidolipids and are proinflammatory. J. Biol. Chem. 2007, 282, 25779-25789, doi:10.1074/jbc.M702277200.

39. Kulkarni, R.; Prasad, A. Exosomes Derived from HIV-1 Infected DCs Mediate Viral trans-Infection via Fibronectin and Galectin-3. Sci. Rep. 2017, 7, 1-14, doi:10.1038/s41598-017-14817-8.

40. Bello-Morales, R.; Praena, B.; de la Nuez, C.; Rejas, M.T.; Guerra, M.; Galán-Ganga, M.; Izquierdo, M.; Calvo, V.; Krummenacher, C.; López-Guerrero, J.A. Role of Microvesicles in the Spread of Herpes Simplex Virus 1 in Oligodendrocytic Cells. J. Virol. 2018, 92, 88-106, doi:10.1128/jvi.00088-18.

41. Lenassi, M.; Cagney, G.; Liao, M.; Vaupotič, T.; Bartholomeeusen, K.; Cheng, Y.; Krogan, N.J.; Plemenitaš, A.; Peterlin, B.M. HIV Nef is secreted in exosomes and triggers apoptosis in bystander CD4+ T cells. Traffic 2010, 11, 110-122, doi:10.1111/j.1600-0854.2009.01006.x.

42. Longatti, A. The dual role of exosomes in hepatitis A and C virus transmission and viral immune activation. Viruses 2015, 7, $6707-6715$.

43. Li, J.J.; Wang, B.; Kodali, M.C.; Chen, C.; Kim, E.; Patters, B.J.; Lan, L.; Kumar, S.; Wang, X.; Yue, J.; et al. In vivo evidence for the contribution of peripheral circulating inflammatory exosomes to neuroinflammation. J. Neuroinflammation 2018, 15, doi:10.1186/S12974-017-1038-8.

44. B, G.; LM, K.; C, M. Directional coupling from the olfactory bulb to the hippocampus during a go/no-go odor discrimination task. J. Neurophysiol. 2010, 103, 2633-2641, doi:10.1152/JN.01075.2009.

45. Natale, G.; Limanaqi, F.; Busceti, C.L.; Mastroiacovo, F.; Nicoletti, F.; Puglisi-Allegra, S.; Fornai, F. Glymphatic System as a Gateway to Connect Neurodegeneration From Periphery to CNS. Front. Neurosci. 2021, 15, 92, doi:10.3389/FNINS.2021.639140.

46. Dikalov, S.I.; Harrison, D.G. Methods for detection of mitochondrial and cellular reactive oxygen species. Antioxidants Redox Signal. 2014, 20, 372-382.

47. Bulua, A.C.; Simon, A.; Maddipati, R.; Pelletier, M.; Park, H.; Kim, K.Y.; Sack, M.N.; Kastner, D.L.; Siegel, R.M. Mitochondrial reactive oxygen species promote production of proinflammatory cytokines and are elevated in TNFR1-associated periodic syndrome (TRAPS). J. Exp. Med. 2011, 208, 519-533, doi:10.1084/jem.20102049.

48. Chen, Y.; Zhou, Z.; Min, W. Mitochondria, oxidative stress and innate immunity. Front. Physiol. 2018, 9, 1487.

49. Subramanian, N.; Natarajan, K.; Clatworthy, M.R.; Wang, Z.; Germain, R.N. The adaptor MAVS promotes NLRP3 mitochondrial localisation and inflammasome activation. Cell 2013, 153, 348-361, doi:10.1016/j.cell.2013.02.054.

50. Onomoto, K.; Onoguchi, K.; Yoneyama, M. Regulation of RIG-I-like receptor-mediated signaling: interaction between host and viral factors. Cell. Mol. Immunol. 2021, 18, 539-555.

51. Heneka, M.T.; Kummer, M.P.; Stutz, A.; Delekate, A.; Schwartz, S.; Vieira-Saecker, A.; Griep, A.; Axt, D.; Remus, A.; Tzeng, T.C.; et al. NLRP3 is activated in Alzheimer's disease and contributes to pathology in APP/PS1 mice. Nature 2013, 493, 674678, doi:10.1038/nature11729.

52. Lee, E.; Hwang, I.; Park, S.; Hong, S.; Hwang, B.; Cho, Y.; Son, J.; Yu, J.W. MPTP-driven NLRP3 inflammasome activation in microglia plays a central role in dopaminergic neurodegeneration. Cell Death Differ. 2019, 26, 213-228, doi:10.1038/s41418018-0124-5. 